\title{
Perícias médicas referentes aos danos pessoais causados por veículos automotores de via terrestre (DPVAT): inadequações e suas consequências
}

\author{
Medical expert avaliation in personal injuries caused by motor \\ vehicles: inadequacies and its consequences
}

\author{
Leonardo Mendes Cardoso(1), Nivaldo dos Santos(2)
}

\begin{abstract}
Cardoso LM, Santos N. Perícias médicas referentes aos danos pessoais causados por veículos automotores de via terrestre (DPVAT): inadequações e suas conseqüências. Saúde, Ética \& Justiça. 2010;15(2):53-62.
\end{abstract}

RESUMO: O Seguro DPVAT (Danos Pessoais Causados por Veículos Automotores de Via Terrestre) é um seguro obrigatório que visa cobrir despesas geradas a partir de gastos financeiros com a saúde física e/ou psíquica decorrentes de sinistros de trânsito de veículos automotores, estando a pessoa afetada como condutora, conduzida ou mesmo fora deste contexto, mas diretamente ligada aos referidos acidentes. Trata-se, portanto, de ação que envolve a esfera cível do Direito brasileiro, não havendo qualquer tipo de ligação com a esfera penal. Óbvio está que envolverá avaliação e valoração de danos à integridade física e/ou à saúde, com a finalidade de sua reparação integral. Assim, a sua quantificação estará voltada para o percentual de área(s) corporal(is) envolvida(s), bem como da importância desta(s) no contexto geral de vida do(a) sinistrado(a). Ainda mais, deverão ser levados em conta fatores para além do explícito na condição, tal como a profissiografia, por exemplo. No entanto, para a esfera penal, a quantificação do dano está bem determinada pelo Artigo 129 do nosso Código Penal brasileiro e se reporta às ofensas à integridade física e/ou à saúde de outrem - e não de si próprio, uma vez que não se importa com as auto-lesões -, dosificando-as como leves, graves, gravíssimas e seguidas de morte, sem se importar com a profissiografia de forma específica, mas tão somente de maneira genérica, de modo a privilegiar o desvendamento acerca da intencionalidade de um ato ilícito. Visto isso, percebe-se a clara diferença existente acerca da atuação pericial entre ambas as condições. Mais especificamente, se uma esfera - a cível - se importa com valorações percentuais e próprias de cada caso e que visem a reparação integral do dano, a outra - penal - se liga às quantificações voltadas para as investigações que conduzam à descoberta relacionada com a intencionalidade e que sejam capazes de permitir a punição de um indivíduo agressor. Médicos peritos legistas não atuam da mesma maneira que os peritos médicos da esfera cível e nem são preparados para tal. Estão eles mais preocupados em prover a justiça com provas materiais concretas que possam elucidar crimes contra a vida (homicídios, tentativas de homicídios, lesões corporais, abortamentos, crimes contra a liberdade sexual etc.), enquanto estes outros tentam demonstrar danos que importem no recebimento de seguros, benefícios previdenciários etc. Portanto, nesse trabalho tentaremos demonstrar a incoerência da obrigatoriedade da avaliação de danos físicos e/ou à saúde de sinistrados a partir de consultas periciais realizadas no âmbito dos institutos médico-legais (IML) e por legisperitos, fugindo-se, assim, da competência destes dois e sendo capaz de gerar interpretações equivocadas do mal provocado.

DESCRITORES: Prova pericial/legislação \& jurisprudência; Seguro por acidentes/legislação \& jurisprudência; Acidentes de trânsito/legislação \& jurisprudência.

\footnotetext{
(1) Médico; Professor de Medicina Legal e Biodireito da Universidade Salgado de Oliveira - campus Goiânia; Professor de Medicina Legal do Instituto de Pós-Graduação - IPOG; Professor do Centro Brasileiro de Pós-Graduação CenBraP.

(2) Doutor em Direito pela PUC-SP, Professor de Direito da UFG e UCG.

Endereço para correspondência: Leonardo Mendes Cardoso. Avenida Tocantins, 1121. Ap. 901. Setor Aeroporto. CEP 74075-100. Goânia - GO.
} 


\section{INTRODUÇÃO}

$\mathrm{N}$ a atualidade brasileira existe o grande problema acerca da realização dos exames periciais referentes ao Seguro de Danos Pessoais Causados por Veículos Automotores de Via Terrestre (DPVAT) ${ }^{1}$ e seu consequente recebimento. Conforme a Lei 6.194/74 $\S 5^{\circ}$, alterada pela Lei 8.441/92:

O Instituto Médico Legal da jurisdição do acidente também quantificará as lesões físicas ou psíquicas permanentes (grifo nosso) para fins do seguro previsto nesta Lei, em laudo complementar, no prazo médio de noventa dias do evento, de acordo com os percentuais da tabela das Condições Gerais do Seguro de Acidente suplementada, nas restrições e omissões desta, pela tabela de acidentes do trabalho e da Classificação Internacional das Doenças.

Tal determinação vincula, de forma compulsória, o julgamento do processo ao laudo pericial realizado no âmbito dos institutos médicolegais de todo o país, devendo ser, portanto, efetuado pelo legisperito, mesmo que este não seja o profissional médico adequadamente preparado para a atividade.

O despreparo se dá por causa da seara de competência destes peritos, uma vez que lidam com a esfera penal, enquanto os danos decorrentes de sinistros de trânsito e merecedores de reparação se fazem valer nos domínios do Direito Civil. Lógico que a valoração dos danos nesta esfera se faz valer de modo totalmente diverso da quantificação existente no foro penal.

Enquanto na primeira teremos a dosificação percentual dos danos sofridos, na segunda ela é qualitativa, levando em conta os graus leve, grave, gravíssimo e seguido de morte. Mais ainda, na primeira condição há que se levar em conta a profissiografia de maneira especificada, enquanto na segunda as atividades laborais são consideradas genericamente.

Associadamente a este problema, temos também que os diversos IMLs nacionais não dispõem de condições ideais para que se misturem as perícias penais e as cíveis, até mesmo por falta de espaços físicos adequados, de materiais ou até mesmo por questões de superlotação das pautas de atendimento. Não nos esqueçamos dos prazos a serem observados em ambas as esferas jurídicas e que, se não devidamente cumpridos, são passíveis de punição para os peritos encarregados, bem como determinantes de prejuízos para os reclamantes.
Questões cruciais ficam suspensas no ar, tal como a questão da responsabilidade de custeio de tais procedimentos. Reportando-nos, de forma comparativa, aos atos periciais em relação aos veículos envolvidos nos sinistros de que ora tratamos - perícia veicular -, não são eles de responsabilidade das próprias seguradoras que formam o pool securitário que assiste ao programa DPVAT? De quem seriam, então, os ônus referentes às perícias médicas necessárias aos trâmites legais destes processos? Do estado ou das seguradoras, já beneficiadas pela recepção de boa parte dinheiro advindo deste seguro compulsório?

A nosso ver, o que existe é uma transferência de responsabilidades, de forma incompreensível e até mesmo absurda, levando-se em conta todos os fatores envolvidos e já expostos. Resta-nos buscar compreender tal processo de desvirtuamento da coisa, bem como os caminhos pelos quais se possa dar a resolução deste impasse.

Assim, partimos para o estudo da questão, tendo em vista a expectativa de um maior alcance social de nossa iniciativa, apesar de constituir-se, tal trabalho, como matéria de cunho científico. Cremos que esse alcance desejado seja, sim, um papel dos trabalhos científicos, pois deles devem brotar as soluções sociais, culturais e políticas ansiadas.

\section{REFERENCIAL TEÓRICO}

Inicialmente teremos como base de nossos estudos a própria lei referente à doutrinação do assunto, qual seja a Lei 6.194/74 (sobretudo o constante do $\S 5^{\circ}$ ), alterada pela Lei $8.441 / 92$. Complementarmente, trabalharemos os escritos de Vanrell e Melo² em "Avaliação das Discapacidades e do Dano Corporal", Vieira e Quintero ${ }^{3}$ em "Aspectos Práticos da Avaliação do Dano Corporal em Direito Civil" e Alcântara ${ }^{4}$ em "Perícia Médica Judicial". Também serão levados em conta artigos dos Códigos Penal, Civil, de Processo Penal e de Processo Civil.

Dados relevantes poderão, subsidiariamente, ser tomados em consideração a partir de páginas da web, bem como de artigos e matérias pertinentes. Tal medida tem o fito de imprimir a este documento científico o senso de atualidade que tais meios possam promover.

\section{METODOLOGIA}

As pesquisas bibliográficas serão o foco mais notado neste trabalho, donde se buscarão proceder 
as análises e deduções. No entanto, outros recursos que se façam necessários serão também privilegiados, tais como leitura e interpretação de revistas e demais publicações das imprensas leiga e científica, páginas da web, entre outros.

Pesquisas cujos temas envolvam o assunto em pauta também participarão colaborando na conclusão deste artigo, com vistas a corroborar as informações nele listadas, interpretadas e que possam permitir-nos uma visão acerca do impacto que tal problemática gera em nosso cotidiano jurídico, pericial e social.

\section{RESULTADOS}

Conforme transcrição de texto exposto na página oficial do aludido seguro obrigatório, qual seja a DPVAT ${ }^{1}$, temos que:

O Seguro DPVAT foi criado pela Lei 6.194 , de 19.12.1974, com o objetivo de garantir às vítimas de acidentes causados por veículos, ou por suas cargas, indenizações em caso de morte e invalidez permanente, e o reembolso de despesas médicas. As indenizações do DPVAT são pagas independentemente de apuração de culpa, da identificação do veículo ou de outras apurações, desde que haja vítimas, transportadas ou não.

Percebe-se, logo à primeira vista e sem muito esforço, que a indenização merecida pelas vítimas dos sinistros que envolvam veículos automotores independe de culpa, tratando-se de processo jurídico nos limites da esfera cível e que visa permitir a reparação integral de um dano sofrido. Não se trata, portanto, de ação penal em que culpa e dolo devam ser discutidos e que, ao fim das contas, interfiram no pagamento ou não de um benefício.

No entanto, há, no $\S 5^{\circ}$ da acima citada lei ${ }^{1}$, a imposição de uma avaliação pericial médica, quantitativa, com a finalidade de avaliação da extensão do dano e suas repercussões, servindo aos interesses das seguradoras. Conforme tal parágrafo, temos que:

$\S 5^{\circ}$ - O Instituto Médico Legal da jurisdição do acidente também quantificará as lesões físicas ou psíquicas permanentes (grifo nosso) para fins do seguro previsto nesta Lei, em laudo complementar, no prazo médio de noventa dias do evento, de acordo com os percentuais da tabela das Condições Gerais do Seguro de Acidente suplementada, nas restrições e omissões desta, pela tabela de acidentes do trabalho e da Classificação Internacional das Doenças.
Nota-se, de forma inequívoca, um avanço aos limites de ação dos institutos médico-legais, uma vez que tais servem aos interesses do foro penal e não do cível, até mesmo em razão da capacitação dos legisperitos, sobretudo em relação à quantificação e valoração dos danos percebidos aos exames periciais.

Invadidas também estão as competências jurídicas, penal e cível, como consequência de uma imposição de lei canhota e que colide frontalmente com as obrigações legispericiais. Resultado disso será a confecção de laudos nem sempre claros e compatíveis com o esperado pelos julgadores legais.

\section{trânsito \\ Acerca do impacto dos sinistros de}

Conforme pesquisa realizada em dezembro de $2006^{5}$ pelo Instituto de Pesquisa Econômica e Aplicada (IPEA) em conjunto com o Departamento Nacional de Trânsito (DENATRAN) e Associação Nacional de Transportes Público (ANTP), os acidentes de trânsito geraram $\mathrm{R} \$ 5,3$ bilhões de perdas em 2001, além dos custos sociais e até mesmo ambientais observados.

Só a partir deste dado já podemos concluir a grandeza do problema que representam os acidentes de trânsito e o quanto de gastos financeiros decorrem dos mesmos. Vale ressaltar que as indenizações são dependentes das perícias que as quantificam e que, em caso da existência ou não de erros ou mesmo de fraudes, tais custos podem ser elevados ou rebaixados, implicando no envolvimento muito maior da própria justiça e do papel do Estado.

Para uma análise mais detalhada do que se encontra envolvido na questão dos sinistros de trânsito (Tabela 1).

Tais dados denotam a relevância do tema, bem como nos remetem ao seu estudo e à elucidação do caso, promovendo o entendimento da problemática exposta e a necessidade urgente de sua solução.

\section{Acerca das ações periciais médicas e suas áreas de competência}

Perícia médica é toda e qualquer ação ou exame realizado por médico, visando a elucidação de fatos que interessem à justiça, provendo-a com dados concretos - ou seja, com provas materiais - acerca de algum objeto em estudo para a consequente formação de um juízo, tanto nas áreas 
administrativas quanto policiais ou judiciárias ${ }^{4}$. As diversas áreas do Direito delas dependem e tais não podem ser realizadas de qualquer modo, a não ser de forma técnico-científica, respeitando-se as qualidades exigidas de um perito, tais como a honestidade, a competência técnica, a idoneidade e a ausência de impedimentos legais e que possam contaminar de nulidade os resultados obtidos.

Tabela 1: Estatísticas dos acidentes de trânsito nas rodovias federais em 2004 e 2005

\begin{tabular}{|c|c|c|c|}
\hline $\begin{array}{l}\text { Item: ( } n^{\circ} \text { de acidentes, } \mathrm{n}^{\circ} \text { de envolvidos por gravidade das lesões, } \\
\text { mortos, feridos e ilesos a cada } 1.000 \text { acidentes) }\end{array}$ & 2004 & 2005 & Var \\
\hline Total acidentes & $112.457,0$ & $109.745,0$ & $-2,4 \%$ \\
\hline № de veículos envolvidos & $190.731,0$ & $184.458,0$ & $-3,3 \%$ \\
\hline № de pessoas envolvidas & $457.409,0$ & $414.663,0$ & $-9,3 \%$ \\
\hline № mortes local & $6.119,0$ & $6.352,0$ & $3,8 \%$ \\
\hline № mortes pós-acidente & $4.067,0$ & $4.064,0$ & $-0,1 \%$ \\
\hline Total mortes & $10.186,0$ & $10.416,0$ & $2,3 \%$ \\
\hline Mortes local / 1.000 acidentes & 54,4 & 57,9 & 3,5 \\
\hline Mortes pós-acidente / 1.000 acidentes & 36,2 & 37,0 & 0,9 \\
\hline Mortes total / 1.000 acidentes & 90,6 & 94,9 & 4,3 \\
\hline № acidentes / morte & 11,0 & 10,5 & $-0,5$ \\
\hline № acidentes / morte local & 18,4 & 17,3 & $-1,1$ \\
\hline № feridos local & $66.117,0$ & $66.066,0$ & $-0,1 \%$ \\
\hline № feridos pós-acidente & $25.678,0$ & $22.816,0$ & $-11,1 \%$ \\
\hline $\begin{array}{l}\text { Total feridos (feridos local + pós-acidente - feridos que vêm a } \\
\text { óbito) }\end{array}$ & $87.728,0$ & $84.818,0$ & $-3,3 \%$ \\
\hline Feridos local / 1.000 acidentes & 587,9 & 602,0 & 14,1 \\
\hline Feridos pós-acidente / 1.000 acidentes & 228,3 & 207,9 & $-20,4$ \\
\hline Feridos total / 1.000 acidentes & 780,1 & 772,9 & $-7,2$ \\
\hline № acidentes / ferido & 1,3 & 1,3 & 0,0 \\
\hline № ilesos local & $385.173,0$ & $342.245,0$ & $-11,1 \%$ \\
\hline $\begin{array}{l}\text { Total ilesos (ilesos local - ilesos que se revelam feridos - ilesos que } \\
\text { vêm a óbito) }\end{array}$ & $359.495,0$ & $319.429,0$ & $-11,1 \%$ \\
\hline Ilesos local / 1.000 acidentes & $3.425,0$ & $3.119,0$ & $-306,5$ \\
\hline Ilesos total / 1.000 acidentes & $3.197,0$ & $2.911,0$ & $-286,1$ \\
\hline № acidentes / ileso & 0,3 & 0,3 & 0,0 \\
\hline № acidentes / ileso & 0,3 & 0,3 & 0,0 \\
\hline
\end{tabular}

Fonte: PRF/MJ, Coordenação Geral de Operações, Divisão de Planejamento Operacional, Núcleo de Estatística, Datatran 2004/2005. Elaboração: Projeto IPEA/DENATRAN a partir da transformação dos dados obtidos na fonte e com incorporação de dados da Pesquisa Completa do Projeto.

Apesar de possíveis nas áreas trabalhista, previdenciária, entre outras, interessa, para fins deste trabalho, a diferenciação específica acerca das áreas cível e penal. Assim sendo, passemos aos conceitos necessários ao melhor entendimento deste artigo. 
Para o foro penal, a perícia deverá buscar dados a partir da análise de vestígios daquilo que compõe o "corpo de delito", uma vez que um ilícito foi cometido e sua intencionalidade, forma de execução e, sobretudo, autoria estão sendo buscados de forma inquestionável para que se faça valer a justiça. Aqui interessarão ações comissivas ou omissivas dolosas, bem com aquelas decorrentes de culpa.

Tais ações periciais, mais qualitativas do que quantitativas a princípio, terão o fito de subsidiar a justiça criminal com as provas materiais concretas do que tenha sido o delito e implicará, após julgamento, na aplicação de penas pertinentes à esfera penal. A quantificação das lesões corporais, porventura existentes, se dará em graduação que varia de leve a gravíssima e seguida de morte.

Para o foro cível interessa a reparação integral do dano, o que por vezes se fará valer através da imposição de penas pecuniárias, tais como pagamento de multas, de pensões, de indenizações, de seguros etc. Aqui se enquadra o nosso tema - seguro DPVAT - e, nesse sentido e como já visto anteriormente, não se coloca em questão o fator "culpa" como requisito para sua percepção. As ações periciais privilegiarão a valoração dos danos de forma quanti-qualitativa, buscando saber sobre o impacto sócio-econômico que provocam, bem como levando-se em conta dados transversais e que possam estar presentes.

Perceba-se, então, que as formas de ação pericial variam conforme os pontos de vista destas duas esferas jurídicas e, cada perito - legisperito e perito médico - deverá apresentar formação profissional e capacitação para a área em que atue. Tal permitirá um melhor desempenho destes profissionais, assim como o respeito às suas habilitações. Mais ainda, evitará erros cometidos a partir do desconhecimento de causa.

Com base nisto, impor a ação de um legisperito, que é basicamente um perito auxiliar da justiça criminal, na área cível é, no mínimo, temerária, em face da fuga de competência e de capacitação que isto implica.

\section{Acerca dos danose das perdas decorrentes dos sinistros de trânsito}

As vítimas dos acidentes de trânsito sofrem, além dos danos patrimoniais - por conta da redução da capacidade de trabalho e da autonomia vivencial - também os danos não patrimoniais, representados por dores e desgostos ${ }^{3}$. Igualmente comum é que se afetem seus aspectos estéticos e com isso sua auto-estima. Assim, temos duas vertentes a serem avaliadas do ponto de vista da reparação: o pagável e o impagável. Lógico pensar que um dia de trabalho possa valer alguns reais, mas impensável quantificar a dor da alma e suas consequências psíquicas, sociais e espirituais.

Trata-se de um universo muito amplo de análise. No âmbito dos IMLs as análises não levam em conta tais perspectivas. O que interessa é o dano em si, apesar de que do laudo decorrerá a punição do agressor. Mas não será tal pena que restituirá o bem perdido. Não se cogitará da reparação material de um dano na esfera penal que dependa de um laudo de lesões corporais, de conjunção carnal ou mesmo cadavérico, por exemplo. Percebe-se, então, o quão diferentes são os enfoques tendose como base do raciocínio as perdas e danos causados em um e outro caso.

Nos sinistros de trânsito teremos, quando acontecidas, lesões que deverão ser quantificadas de forma percentual e levando-se em conta o impacto que tais representam sobre o cotidiano da vítima: deixou esta de produzir para sua subsistência e dos que dela porventura dependam? Restou algum dano estético? Tal prejuízo estético liga-se diretamente ao seu ganho financeiro? Houve algum tipo de deficiência? Em que grau? E por aí seguem as mais variadas formas de abordagem, na tentativa de que sejam computadas as perdas financeiras e o quanto, no conjunto com os demais danos, deve merecer de indenização.

Para além do já abordado, quando da morte da vítima, quanto valeria, para os seus herdeiros, a sua vida ceifada de forma precoce? O dano moral dos herdeiros não poderia ser levado mais em conta do que a perda física do ente querido. E para questões dessa natureza não se aconselha jogar nas mãos dos legisperitos as avaliações de tais perdas e danos ${ }^{3}$.

Há ainda a necessidade da avaliação do nexo de causa de forma diferente nas duas esferas, cível e penal, de forma que nesta primeira possam ser medidas suas repercussões sobre a vida da vítima, enquanto na segunda o que se pretende é investigar a intencionalidade do agressor.

Em relação aos danos que interessam à esfera cível, temos que levar em conta determinados conceitos indispensáveis à análise pericial e que contarão ao fim das contas para que se estipulem os valores das indenizações devidas. São eles: invalidez, deficiência, debilidade, incapacidade e grau de discapacidade, caráter permanente, caráter provisório, total ou parcial.

A partir do normal poderemos ter uma perfeita noção do anormal. Assim, um determinado indivíduo 
é capaz para exercer determinada atividade quando reúne as condições morfopsicofisiológicas compatíveis com o pleno desempenho de tais atividades, sem que isto implique obrigatoriamente em ausência de doença e/ou de lesão. Se houver incapacidade, ela será total quando impedir o exercício da profissão habitual, das atividades habituais e também de outras atividades laborais. E será parcial quando impedir o exercício da profissão habitual, permitindo reabilitação para outras atividades laborais.

Se a incapacidade é reversível, será dita temporária, caso contrário, será considerada permanente. Em casos de incapacidade total e permanente, diremos que o indivíduo se encontra inválido, uma vez que se encontrará impossibilitado de forma definitiva para que possa prover sua própria subsistência e/ou daqueles que porventura legalmente dele dependam.

Debilidade é geralmente conceituada como sendo o enfraquecimento de uma força física, funcional ou mental. Seria algo próximo a um déficit e dele decorreria a deficiência, uma vez que algo irá funcionar precariamente e de forma comprometida. Há que se perceber que todos estes conceitos são estreitamente interligados e de forma sutil se interpõem, se entrelaçam. Quantificá-los, eis o problema!

Acerca dos graus de discapacidade, dizem respeito ao nível de perda das capacidades para a atividades da vida diária (AVD), indo do grau 1 - referente à discapacidade nula - ao grau 5, que se refere à discapacidade muito grave, na qual os sintomas, sinais e/ou sequelas impossibilitam a realização das $\mathrm{AVD}^{2}$.

Vale lembrar, nesse momento, que a lei que estamos a analisar - do seguro DPVAT - fala inequivocamente que os IMLs "quantificarão as lesões físicas ou psíquicas permanentes (grifo nosso)". Não se falou em tal ação pericial de outra forma que não aquelas em que estejam envolvidas as lesões físicas ou psíquicas já consideradas como permanentes. Ressaltemos, então, que permanente quer dizer já consolidado, estável e não recuperável.

Assim considerando, os exames periciais relativos aos sinistros de trânsito e que não tenham se demonstrado como motivados por lesões já consideradas como permanentes fugiriam à regra e poderiam ter suas análises recusadas pelos legisperitos. Mas este é apenas um dos detalhes que envolvem a questão e talvez o menor deles, haja vista a relevância do que tentamos provar, ou seja, a não observância dos limites de competência dos institutos médico-legais e de seus legisperitos em relação a essa atividade pericial, totalmente cível.

\section{Acerca das avaliações periciais médicas em causas que envolvam o DPVAT}

Os atos periciais são regidos por legislações específicas, havendo determinações quanto aos ritos a serem seguidos, tanto na esfera penal quanto na cível. Assim, há clara diferenciação quanto ao exposto nos respectivos códigos processuais. As competências estão ali bem definidas e dizem respeito às particularidades pertinentes a cada uma dessas áreas da ação jurídica.

Segundo o Código de Processo Penal (CPP) ${ }^{6}$, as perícias deverão ser realizadas sempre que um ato ilícito deixar vestígios, os quais, em conjunto, comporão o "corpo de delito" (artigo 158), não as suprindo nem a confissão do acusado. Já o Código de Processo Civil $(\mathrm{CPC})^{7}$ fala da necessidade de se provar um fato (artigo 145), sem que se cogite sobre ilicitude ou mesmo de alguém estar sendo criminalmente acusado por tal ilícito.

De acordo com o CPP ${ }^{6}$, em seu artigo 159 - nova redação - o perito será oficial e designado pela autoridade competente à frente do caso. $\mathrm{Na}$ falta deste, dois peritos deverão ser nomeados entre os profissionais com curso superior e qualificação na área em análise (artigo $159 \S 1^{\circ}$ ). Complementarmente, caberão, observadas as regras legais, as indicações de assistentes técnicos auxiliares das partes envolvidas. O interesse, nesta esfera, é público.

Conforme o $\mathrm{CPC}^{7}$, o perito será pago pela parte que requereu o exame, pelo autor ou por ambos, ou mesmo determinado de ofício pelo juiz (artigo 33). Cada parte poderá nomear um ou mais assistentes técnicos, arcando com os honorários combinados com os mesmos. Os interesses envolvidos nesses casos são privados.

\section{Conforme Vieira e Quintero ${ }^{3}$ :}

Sempre que um perito médico é solicitado no sentido de proceder a uma avaliação de danos corporais, o que se the pede é que, recorrendo aos seus conhecimentos no âmbito da Medicina, à preparação científica e técnica que a sua formação médicas e pericial the confere, defina num determinado quadro jurídico (em Direito Penal, Civil, do Trabalho, Administrativo, etc.), quais as lesões e/ou sequelas de que uma determinada vítima ficou portadora, susceptíveis de (consoante a área do direito em que a perícia 
Cardoso LM, Santos N. Perícias médicas referentes aos danos pessoais causados por veículos.

decorre) serem objeto de sanção penal, da atribuição de uma indenização ou de justificarem, por exemplo, a concessão de determinadas regalias e benefícios (fiscais, sociais ou outros). Significa isto que a avaliação de danos corporais se processa (deve processar) de formas distintas consoante o domínio do Direito em que se concretiza. Os mesmos danos poderão, assim, ter uma abordagem, uma apreciação, uma valoração pericial diversa, consoante o domínio do Direito onde essa avaliação pericial se processa. Isto, repete-se, porque os princípios jurídicos que definem os danos a avaliar são diferentes para cada um deles.

No âmbito do Direito Civil o princípio jurídico que orienta a avaliação dos danos corporais é o da reparação integral dos danos. Significa isto que em Direito Civil todos os danos, desde que tenham uma dignidade suficiente para merecerem a tutela do direito, devem ser avaliados e indenizados ( $p$. 36-7).

Ainda, da mesma obra acima citada, os peritos devem ter plena consciência da possibilidade de serem responsabilizados - civil, disciplinar e criminalmente em casos mais extremos - por atuações ilícitas e culposas, gerando uma avaliação insuficiente ou incorreta dos danos por eles apreciados. mentais

Da valoração dos danos físicos e/ou

O Código Penal ${ }^{9}$ brasileiro, em seu artigo 129, prevê a quantificação das chamadas lesões corporais através de uma classificação que vai desde o grau leve ao gravíssimo e seguido de morte. Tal quantificação diz respeito a uma atitude comissiva ou omissiva dolosa que possa "ofender a integridade física ou a saúde de outrem". Não há previsão acerca das auto-lesões neste âmbito jurídico.

Já o Código Civil se baseia numa valoração percentual, conforme tabela específica e "a quantia que se apurar, tomará por base o percentual da incapacidade de que for portadora a vítima, de acordo com os critérios estabelecidos no $\S 1^{\circ}$, e seus incisos, do art. $3^{\circ}$ da Lei n. ${ }^{\circ} 6.194 / 74^{1}$, e com a tabela de Danos Corporais Totais, constante do anexo daquela Lei, tendo como indenização máxima a importância segurada vigente na época da ocorrência do sinistro." Conforme o exposto na página da Superintendência de Seguros Privados $^{10}$.

Abaixo, as Tabelas 2-6, traz informações sobre indenizações.
Tabe 2: Tabela de valores para indenizações

\begin{tabular}{l|l|}
\hline Morte & $\mathrm{R} \$ 13.500,00$ \\
\hline $\begin{array}{l}\text { Invalidez total ou debilidade de } \\
\text { membros Até }\end{array}$ & $\mathrm{R} \$ 13.500,00$ \\
\hline $\begin{array}{l}\text { Crédito para tratamento } \\
\text { médico,fisioterapia, compra de } \\
\text { remédios e produtos ortopédicos }\end{array}$ & $\mathrm{R} \$ 2.700,00$ \\
\hline
\end{tabular}

\section{Tabela 3: Indenizações}

\begin{tabular}{l}
\hline Perda total - $100 \%$ = R\$ $13.500,00$ \\
\hline Perda total da visão de ambos os olhos \\
Perda total do uso de ambos os braços \\
Perda total do uso de ambas as pernas \\
Perda total do uso de ambas as mãos \\
Perda total do uso de um braço e uma perna \\
Perda total do uso de uma das mãos e um dos pés \\
Perda total do uso de ambos os pés \\
Alienação mental total incurável
\end{tabular}

Tabela 4: Perda parcial - parte superior

\begin{tabular}{|c|c|c|}
\hline Perda total da visão de um olho & $30 \%$ & $\mathrm{R} \$ 4.050,00$ \\
\hline Quando não tiver a outra visão & $70 \%$ & $R \$ 9.450,00$ \\
\hline Mudez Incurável & $0 \%$ & $\mathrm{R} \$ 6.750,00$ \\
\hline $\begin{array}{l}\text { Fratura não consolidada do } \\
\text { maxilar inferior }\end{array}$ & $20 \%$ & $\mathrm{R} \$ 2.700,00$ \\
\hline $\begin{array}{l}\text { Anquilose total de um dos } \\
\text { cotovelos }\end{array}$ & $25 \%$ & $R \$ 3.375,00$ \\
\hline $\begin{array}{l}\text { Anquilose total de um dos } \\
\text { punhos }\end{array}$ & $20 \%$ & $\mathrm{R} \$ 2.700,00$ \\
\hline $\begin{array}{l}\text { Surdez total incurável de um } \\
\text { ouvido }\end{array}$ & $20 \%$ & $R \$ 2.700,00$ \\
\hline $\begin{array}{l}\text { Surdez total de ambos os } \\
\text { ouvidos }\end{array}$ & $40 \%$ & $R \$ 5.400,00$ \\
\hline $\begin{array}{l}\text { Anquilose total de um dos } \\
\text { ombros }\end{array}$ & $25 \%$ & $\mathrm{R} \$ 3.375,00$ \\
\hline $\begin{array}{l}\text { Fratura não consolidada de um } \\
\text { dos braços }\end{array}$ & $30 \%$ & $R \$ 4.050,00$ \\
\hline Perda total de um dos braços & $70 \%$ & $R \$ 9.450,00$ \\
\hline Anquilose total de um quadril & $20 \%$ & $R \$ 2.700,00$ \\
\hline Perda total de uma das mãos & $60 \%$ & $R \$ 8.100,00$ \\
\hline Perda do dedo mínimo & $12 \%$ & $\mathrm{R} \$ 1.620,00$ \\
\hline Perda do dedo anular & $09 \%$ & $\mathrm{R} \$ 1.215,00$ \\
\hline Perda do dedo médio & $12 \%$ & $\mathrm{R} \$ 1.620,00$ \\
\hline Perda do indicador & $15 \%$ & $R \$ 2.025,00$ \\
\hline Polegar & $18 \%$ & $\mathrm{R} \$ 2.430,00$ \\
\hline Metacarpiano & $25 \%$ & $R \$ 3.375,00$ \\
\hline
\end{tabular}


Tabela 5: Perda parcial - parte inferior

\begin{tabular}{|l|l|l|}
\hline Fratura não consolidada do fêmur & $50 \%$ & $R \$ 6.750,00$ \\
\hline Fratura não consolidada de uma perna & $25 \%$ & $R \$ 3.375,00$ \\
\hline Perda total do uso de uma perna & $70 \%$ & $R \$ 9.450,00$ \\
\hline Fratura não consolidada da rótula & $20 \%$ & $R \$ 2.700,00$ \\
\hline Anquilose total de um joelho & $20 \%$ & $R \$ 2.700,00$ \\
\hline Anquilose total de um dos tornozelos & $20 \%$ & $R \$ 2.700,00$ \\
\hline Fratura não consolidada de um pé & $20 \%$ & $R \$ 2.700,00$ \\
\hline Perda total de um dos pés & $50 \%$ & $R \$ 6.750,00$ \\
\hline Perda parcial de um dos (todos os dedos uma parte do mesmo pé) & $25 \%$ & $R \$ 3.375 .00$ \\
\hline Amputação do primeiro dedo do pé & $10 \%$ & $R \$ 1.350,00$ \\
\hline Amputação de qualquer outro dedo do pé & $03 \%$ & $R \$ 405,00$ \\
\hline
\end{tabular}

Tabela 6: Indenização referente a encurtamento de uma das pernas

\begin{tabular}{|l|c|c|}
\hline 5 centímetros ou mais & $15 \%$ & $\mathrm{R} \$ 2.025,00$ \\
\hline 4 centímetros & $10 \%$ & $\mathrm{R} \$ 1.350,00$ \\
\hline 3 centímetros & $06 \%$ & $\mathrm{R} \$ 810,00$ \\
\hline \multicolumn{2}{c}{$\begin{array}{c}\text { Menos que três centímetros não tem } \\
\text { indenização }\end{array}$} &
\end{tabular}

Deve restar clara a diferenciação de valores ou penas a serem cobrados nas duas esferas em comento. Tal atitude deverá levar a uma tomada de consciência em relação ao caso e a uma percepção lógica e racional de que as competências são distintas, podendo a inobservância destas levar a prejuízos para a efetuação da justiça.

\section{CONCLUSÃO}

Para a conclusão deste artigo científico, optamos por inserir o texto jornalístico ${ }^{11}$ abaixo, apontando fraudes:

Em razão do elevado número de ações de cobrança do Seguro de Danos Pessoais Causados por Veículos Automotores de Vias Terrestres - o DPVAT -, mais conhecido como 'Seguro Obrigatório', ajuizadas ultimamente e a comprovação do uso de documentação falsa para sua obtenção, foi deliberado ontem, no sentido de exigir nestas ações, a via original do boletim de ocorrência, prontuário médico e laudo médico oficial especificando a lesão sofrida e a extensão da incapacidade decorrente dela (grifo nosso). A deliberação foi tomada durante reunião na Diretoria do Foro de Goiânia, em que participaram os magistrados com atuação nas Varas de Família, Sucessões e Cível, Juizados Especiais Cíveis e nas Turmas Julgadoras Mistas da Comarca de Goiânia. Considerando ainda que o pagamento do seguro DPVAT é efetuado pelas seguradoras, as quais são ressarcidas pela Fenaseg, utilizando-se do fundo formado pelos valores que cada proprietário de veículo recolhe a título de seguro obrigatório, observa o juiz Carlos França. $O$ assunto será encaminhado também à Corregedoria Geral da Justiça. (Cf. Jornal Diário da Manhã Online)

Em rápida navegação pela web, podemos constatar que não se trata de fato isolado, mas comumente verificado e que envolve, como se pode ler no documento acima, a ação pericial médica de forma bem evidenciada.

Relembrando todos os argumentos expostos anteriormente, vimos que as perícias se fazem valer de formas bem distintas nas esferas penal e cível, sobretudo no tocante às quantificações decorrentes das avaliações dos danos sofridos. No foro penal o que interessa é o desvendamento de um ilícito, culminando com a imposição de uma pena privativa de liberdade ou mesmo de uma medida sócioeducativa para o agressor. No cível, referente ao DPVAT, o que se deseja é a reparação integral do dano, mediante pagamento de uma indenização à vitima de um sinistro de trânsito.

Há legislação específica para cada âmbito jurídico e as regras de um não se aplicam ao outro, sobretudo por defenderem pontos de vista bem particulares a cada um. Enquanto na esfera penal privilegia-se o interesse público, na cível o que se vê é o privilégio dos interesses privados, uma vez que há duas partes em litígio.

Podemos ainda citar que o DPVAT é um seguro obrigatório e que um pool de empresas privadas de seguro, ditas seguradoras consorciadas, se beneficiam financeiramente da exploração deste. Inferimos disto que a responsabilidade pela realização das perícias e pagamento dos honorários dos peritos deveriam ser de responsabilidade 
destas mesmas seguradoras e não do Estado, o qual acaba por delegar esta tarefa, de forma no mínimo equivocada, aos institutos médico-legais e seus legisperitos.

Não se levam em conta os problemas que daí decorrem, tais como a superlotação dos IMLs já atuantes acima dos limites de suas capacidades físicas e técnicas, a falta de condições técnicas para a realização destes exames, a sobrecarga dos profissionais que lá trabalham, o desvio de função legispericial, a não capacitação destes peritos para a tarefa que lhes é incumbida, o desrespeito às competências previstas em lei, entre outros fatores.

O Brasil já conta com diversos cursos de pósgraduação na área pericial médica, sendo inúmeros os médicos com preparo suficiente para tal trabalho e que, de forma organizada e fiscalizada pela própria justiça, poderiam ser designados para a execução efetiva e célere das perícias necessárias para a solução dos milhares de processos relacionados ao seguro DPVAT e estagnados em face de tanta burocracia.

Retirar tais atos periciais da responsabilidade dos institutos médico-legais se faz urgente e um diálogo com entidades específicas - Associação Brasileira de Medicina Legal, Ordem dos Advogados do Brasil, Ministérios Públicos, por exemplo com certeza ajudaria na elucidação e resolução deste impasse. Beneficiados seriam todos os que, recolhendo tal seguro de forma compulsória, veem prejudicados os seus direitos. Igualmente prejudicados ficam os legistas, obrigados a realizar tarefas que extrapolam suas competências e os sobrecarregam com trabalho extra. Prejudicados estão também todos os peritos médicos que percebem seu campo de trabalho reduzido por uma ação que fere a legislação vigente.

Por fim, a própria qualidade dos documentos resultantes das ações periciais sofre com a inadequação deste trabalho, restando ao contribuinte ver ferido o seu direito de ampla defesa e de um cumprimento justo do que lhe é devido.

Cardoso LM, Santos N. Medical expert avaliation in personal injuries caused by motor vehicles: inadequacies and its consequences. Saúde, Ética \& Justiça. 2010;15(2):53-62.

\begin{abstract}
The DPVAT Insurance is a compulsory insurance that aims to cover expenses generated from financial to physical and/or psychological claims arising from the transit of vehicles, being the person affected the driver, or even driven out of context, but directly related to these accidents. It is therefore an action that involves the civil sphere of the Brazilian law, no type of connection to the criminal sphere. It is obvious that it involves evaluation and assessment of damage to physical integrity and / or health, in order to repair them integrally. Thus, its quantification is dedicated to the percentage of body area(s) involved and the importance of this in the general context of the life affected. Even more, it should be taken into account factors beyond the explicit condition, job profile graph, for example. However, in (for) the criminal sphere, the quantum of damage is well established by Article 129 of our Brazilian Penal Code and harm to physical integrity and/or health of others - and not for himself, since it does not care about self-injury -, dosed them as mild, severe, serious and followed by death, no matter the job profile graph in a specific way, but just so generic, so as to favor the unmasking of the intentionality of a tort. Given this, we find a clear difference on performance between the two expert conditions. More specifically, if a sphere - the civil law - cares about assessments and percentage of each case and to the full repair of the damage, the other - criminal - is bound to focus measurements for investigations leading to the discovery related to intentionality and are able to allow the punishment of an individual offender. Legal medicine specialists does not act the same way that medical experts of the civil sphere and are not prepared for this. They are more concerned about providing justice to the concrete material evidence that may elucidate crimes against life (murder, attempted murder, bodily injury, miscarriage, crimes against sexual freedom etc.), while the others try to show that damage in receiving care insurance, etc benefits. Therefore, in this work we demonstrate the inconsistency of mandatory assessment of injury and/or the health of victims from expert consultations carried out under the legal medicine institutes (IML) and legal medicine specialist, escaping, therefore, the responsibility of these two and being able to generate interpretations of harm caused.
\end{abstract}

KEYWORDS: Expert testimony/legislation \& jurisprudence; Insurance, accidents/legislation \& jurisprudence; Accidents, traffic/legislation \& jurisprudence.

\title{
REFERÊNCIAS
}

1. Seguros de Danos Pessoais Causados por Veículos Automotores de Via Terrestre (DPVAT). Lei nº 6.194, de 19 de dezembro de 1974. Disponível em: http:// www.dpvatseguro.com.br/conheca/informacoes.asp 
Cardoso LM, Santos N. Perícias médicas referentes aos danos pessoais causados por veículos.

2. Alcântara HR. Perícia judicial médica. São Paulo: Guanabara Koogan; 2006.

3. Vanrell JP; Melo RB. Avaliação das discapacidades e do dano corporal. Leme: Mizuno; 2007.

4. Vieira DN, Quintero JA. Aspectos práticos da avaliação do dano corporal em direito civil. Coimbra: Biblioteca Seguros; 2008.

5. Impactos sociais e econômicos dos acidentes de trânsito nas rodovias brasileiras. Brasília: IPEA, DENATRAN, ANTP; 2006. Disponível em: http:// www.denatran.gov.br/publicacoes/download/ custos_acidentes_transito.pdf

6. Brasil. Código de Processo Penal: Capítulo II - Do Exame de Corpo de Delito, e das Perícias em Geral [citado em 13 ago. 2009]. Disponível em http://www. planalto.gov.br/CCIVIL/Decreto-Lei/Del3689.htm.
7. Brasil. Código de Processo Civil: Capítulo II, Seção III - Das Penas e das Multas; Capítulo V, Seção II Do Perito [citado em 13 ago. 2009]. Disponível em http://www.planalto.gov.br/CCIVIL/Leis/L5869.htm.

8. Brasil. Ministério da Fazenda. SUSEP. Seguro DPVAT [citado em 30 jul. 2009]. Disponível em: http://www. susep.gov.br/menuatendimento/dpvat.asp.

9. Brasil. Código Penal: Capítulo II - Das Lesões Corporais [citado em 13 ago. 2009]. Disponível em: http://www.planalto.gov.br/CCIVIL/Decreto-Lei/ Del2848.htm.

10. Superintendência de Seguros Privados.

11. Texto sobre fraudes [citado em 30 jul. 2009]. Disponível em: http://v6.dm.com.br/impresso/7846/ cidades/38391,medidas_para_combater_fraudes_ no_dpv at 